\section{"Prismas de percepção": múltiplas leituras das campanhas em saúde no Nordeste brasileiro}

\author{
"Prisms of Perception": multiple readings of mass \\ media health messages in Northeast Brazil
}

\author{
1 Universidade de Fortaleza, \\ Fortaleza, Brasil. \\ Correspondência \\ K. C. B. M. Diógenes \\ Mestrado em Saúde Coletiva, \\ Universidade de Fortaleza. \\ Av. Washington Soares 1321, \\ Fortaleza, CE 60811-905, \\ Brasil. \\ katiamachadofisioterapia@ \\ hotmail.com
}

\section{Abstract}

This anthropological study from February 2009 to November 2010 revealed the comprehension and cultural critique of three mass media health campaigns in Northeast Brazil. Twenty-four ethnographic interviews were conducted, exploring the iconographic and semantic content of the campaigns in the Dendê community in Fortale$z a$, Ceará State, Brazil. The authors used Content Analysis; Systems of Signs, Significance, and Actions; and Contextualized Semantic Interpretation. There is a gap between the elaboration and reception of messages. Multiple interpretations occur (proximal reading, kaleidoscope of comprehension, and distant reading), depending on the reader's cognitive proximity to (or detachment from) the message. This "perceptual plasticity" arises from the creativity of popular imagination. Health professionals who hear rather than dismiss the "recipient's" subjective voice, which re-signifies authoritative messages, can penetrate the perception of the recipient's "visual world". In the context of poverty, this re-framing is essential for people to comprehend and proactively defend their own health.

Health Communication; Poverty; Semantics
Kátia Castelo Branco Machado Diógenes 1 Marilyn Nations 1

\section{Introdução}

Campanhas de comunicação em saúde se baseiam no modelo biomédico ${ }^{1}$ - focado na doença-reproduzindo a voz governamental 2 . Esse modelo hegemônico impõe comportamentos "saudáveis" e exige adesão popular à mensagem veiculada ${ }^{3}$, utilizando linguagem bancária ${ }^{4} \mathrm{e}$ unidirecional.

A compreensão humana, porém, é diversificada, ampla e complexa, evidenciando uma multivocalidade 5 . É influenciada por fatores socioculturais e imaginário popular 6 através de experiências no mundo moral local 7,8. O receptor pode "não aderir" à mensagem da campanha; que desconsidera histórias vividas, crenças e valores, estando distante da experiência cotidiana 3. O olhar é o principal meio para captar informações 9. Devido às múltiplas leituras dos cartazes, lacunas emergem entre a percepção do criador e receptor. É preciso mudar o pensamento, percepção e valor mecanicista ${ }^{1}$ para uma concepção holística da realidade. Objetivamos desvelar a leitura crítica dos receptores-cidadãos no Nordeste brasileiro, de campanhas em saúde. 


\section{Metodologia}

\section{Dendê: comunidade à "margem"}

Essa pesquisa antropológica foi realizada, de fevereiro de 2009 a novembro de 2010, na comunidade de baixa renda do Dendê, Fortaleza, Ceará, Nordeste brasileiro. À margem do poluído Rio Cocó, o Dendê é excluído da sociedade privilegiada ao seu redor. Na última década, houve uma explosão populacional na comunidade de $17,8 \%$ anual - superior à média de $1,2 \%$ da capital 10 , acentuando a estratificação social. A iniquidade socioeconômica é evidente 10 entre a próspera Rua do Comércio e a miserável Baixada, imersa na lama do mangue, com casas precárias e esgoto a céu aberto.

\section{Desvelando leituras múltiplas}

As pesquisadoras imergiram no Dendê, acompanhadas pelos agentes de saúde, moradores da comunidade, facilitando a identificação de informantes. Enfrentaram dificuldades como chuvas intensas, tiroteios e assaltos. Horários e dias das visitas domiciliares foram restringidos aos de menores riscos e uma área de alta periculosidade foi evitada.

Numa triagem aleatória, 24 informantes-alvos das campanhas, $50 \%$ da Baixada e $50 \%$ da Rua do Comércio, foram selecionados de acordo com critérios pré-estabelecidos: fumantes há mais de 10 anos e cuidadores de crianças $>21$ anos. Esses sujeitos foram subdivididos pelo nível de escolaridade: analfabetos/baixa escolaridade ( $<4$ a série) ou alfabetizados ( $\geq$ 5a série). Os 24 informantes realizaram 36 leituras de cartazes, 12 do tabagismo; 24 de dengue e queimadura.

Entrevistas etnográficas exploraram o significado semântico e iconográfico das campanhas utilizando perguntas norteadoras: "O que você entende dessa foto?”; "Qual foto chama mais sua atenção?”. Foram avaliadas as campanhas nacional do tabagismo (2004-2008), regional de dengue e local de queimadura na infância. Imagens ampliadas dos cartazes das campanhas incentivaram a narrativa livre do morador. As entrevistas foram gravadas e transcritas. Foram utilizados Análise de Conteúdo Temática de Bardin 11 e Interpretação Semântica Contextualizada de Bibeau \& Corin 12 para analisar e interpretar os dados.

A pesquisa, conforme a Resolução $n^{\circ}$. 196/96 do Conselho Nacional de Saúde, foi aprovada pelo Comitê de Ética da Universidade de Fortaleza (nº 10-001). Os nomes dos informantes são fictícios.

\section{Resultados}

\section{Prismas de percepção humana}

São múltiplas as leituras das três campanhas: "próxima”, “caleidoscópio de compreensão" e "distante". A interpretação do conteúdo iconográfico e semântico depende da proximidade cognitiva do leitor da mensagem das campanhas. A seguir as leituras pela ótica dos moradores do Dendê.

\section{Leitura próxima}

Apenas três (8,3\%) leituras dos moradores replicaram a mensagem pretendida pelo Ministério da Saúde, embora nenhuma em sua completude. Lívia, 21, fumante há 15, sabe que o cigarro agride seu corpo: "Essa foto do pulmão encharcado de fumaça... não presta pra nada. Será que o meu tá assim?". Compreende que a imagem de um bebê prematuro é provocada pelo fumo: “ $A$ mãe fumou bastante e ele nasceu prematuro... por causa do cigarro!". Nádia, fumante desde os 12, espanta-se ao ver a foto de um rapaz traqueostomizado por câncer de laringe: "Aquele rapaz tá com problema na garganta. É do cigarro?... Dá câncer!”. Das três, Maria, 2o grau completo, aproxima-se da linguagem tecnicista da campanha da dengue: "Num é pra deixar água parada... tenho consciência que se deixar, o mosquito vem na minha casa...".

\section{Caleidoscópio de compreensões}

A maioria, $69,4 \%$, reinterpretou a mensagem do Ministério da Saúde baseada na experiência cotidiana. Moradores descreveram um "caleidoscópio de compreensão" com infinitas combinações. Essa "plasticidade perceptual" fragmenta a ideia entre a emissão e recepção pela população, sendo "distorcida" por forças mediadoras individuais e coletivas. Os sentidos da propaganda são reinterpretados baseados no conhecimento e experiência prévia. A compreensão da mensagem gira em torno da sabedoria local e não, necessariamente, à escolaridade formal do leitor. Moradores analfabetos percebem relevância na campanha, mesmo sem sua interpretação ser equivalente à ideia governamental. Dona Flávia, 64 , analfabeta, fumante desde os oito, olha a imagem da necrose na perna de um fumante crônico. Emocionada, não associa a "ferida braba" à campanha do tabagismo, mas sim à leishmaniose cutânea, doença epidêmica no Ceará: “Acho que isso é ferida braba! Às vezes a pessoa pega de picada de inseto...".

A leitura - "sem bordas" ou "limites" - de Dona Regina, fumante crônica e analfabeta, foge da 
interpretação pretendida. Numa junção aleatória, inédita e criativa une duas imagens da campanha contra tabagismo: uma ponta de cigarro (Figura 1) com uma perna amputada de um homem numa cadeira de rodas (Figura 2). Em seu imaginário fértil, transfigura a ponta do cigarro numa prótese de plástico. Numa "cirurgia” cognitiva, Dona Regina, enxerta a prótese-cigarro no coto da perna que resta: "Pensei que era a perna de uma pessoa que nem aquele homem acolá!", sentindo-se satisfeita com sua "operação" bem sucedida.

\section{Leitura distante}

Das 36 leituras, 8 (30,5\%) foram distantes do pretendido nas campanhas. Para os moradores que não sabem ler ou não tiveram vivências relevantes, a compreensão é mínima. Seis leituras

\section{Figura 1}

Campanha nacional contra o tabagismo.

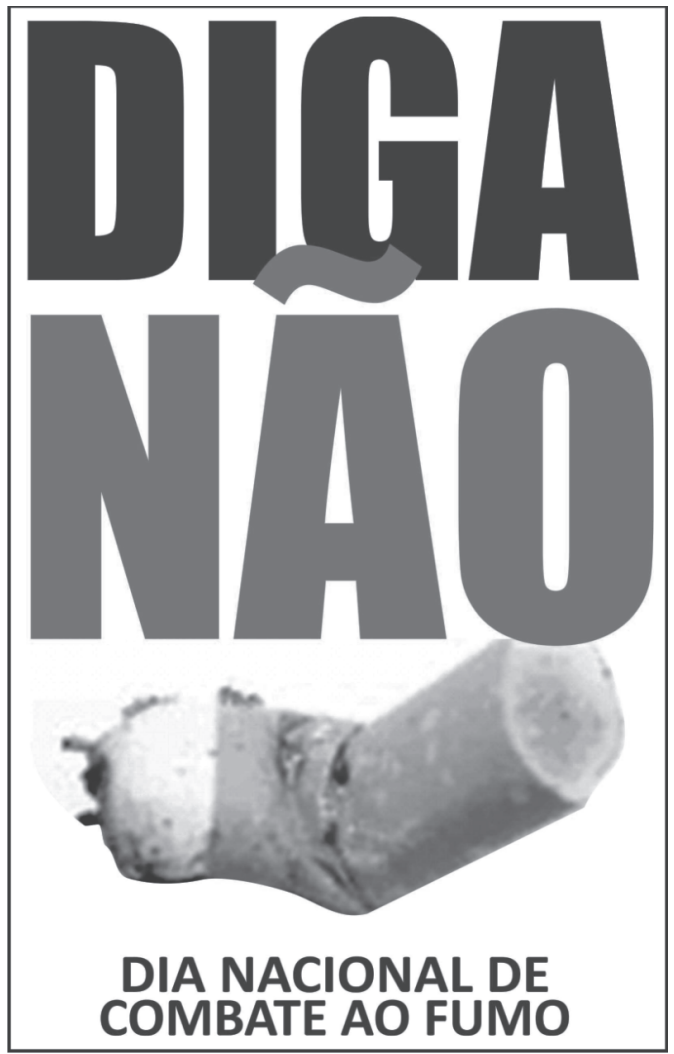

Fonte: Instituto Nacional de Câncer/Ministério da Saúde.
Figura 2

Vítima do tabagismo.

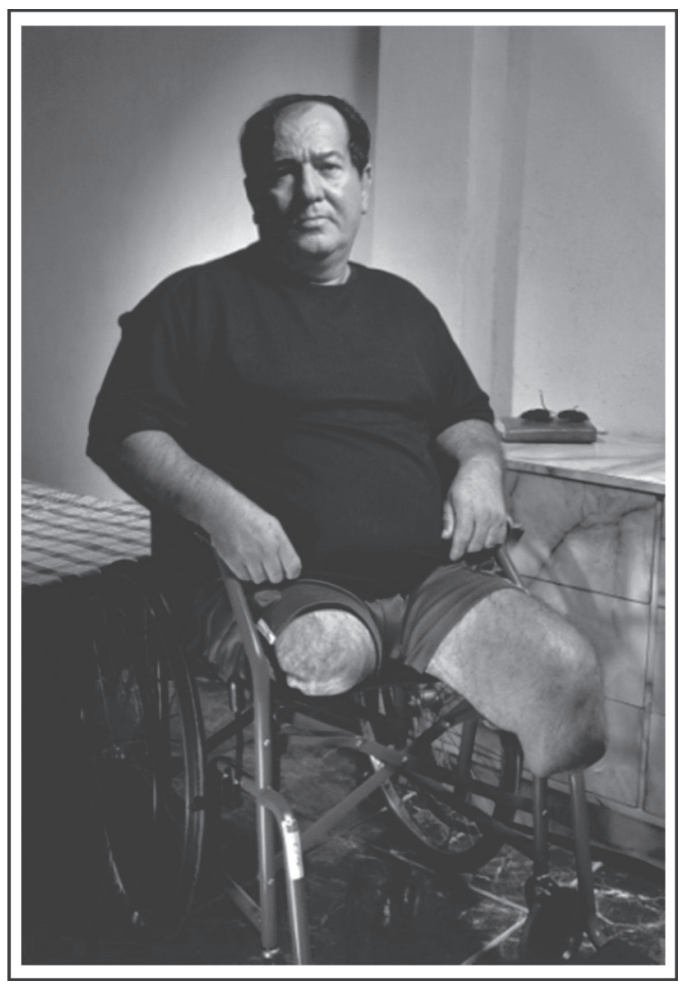

Fonte: Instituto Nacional de Câncer/Ministério da Saúde.

foram de moradores da Rua do Comércio. Dona Antônia, 60, 1a série, não tem sequer aproximação cognitiva com a campanha da dengue: "Num respondo porque não sei... Esse negócio da campanha, não sei nada...”. Apesar de ter estudado até a 5 a série, Sr. Marcos, 69, tabagista há 54, percebese perplexo diante da imagem do cigarro curvado sugerindo impotência sexual: "Num sei dizer nada... num entendo”. Laura, 44, não compreende a imagem do pulmão com câncer: "Parece o pescoço de um peru (risos)...! Olha as asas dele...”.

Dona Sônia, 64, mãe de 10 filhos, fita a imagem da criança de costas nuas na campanha contra queimadura (Figura 3) e questiona: " $\mathrm{Ta}$ tuage? É isso?”. Confunde as imagens dos fósforos, ferro, chaleira etc., com tatuagens. A criança desnuda de costas, assemelha-se à Campanha de Exploração Sexual Infantil divulgada em aeroportos e pontos turísticos cearenses. Essa percepção é confirmada na indignação da jovem mãe Cláudia: "Não acho certo dispor a menina nua aqui!". 
Figura 3

Queimadura na infância.

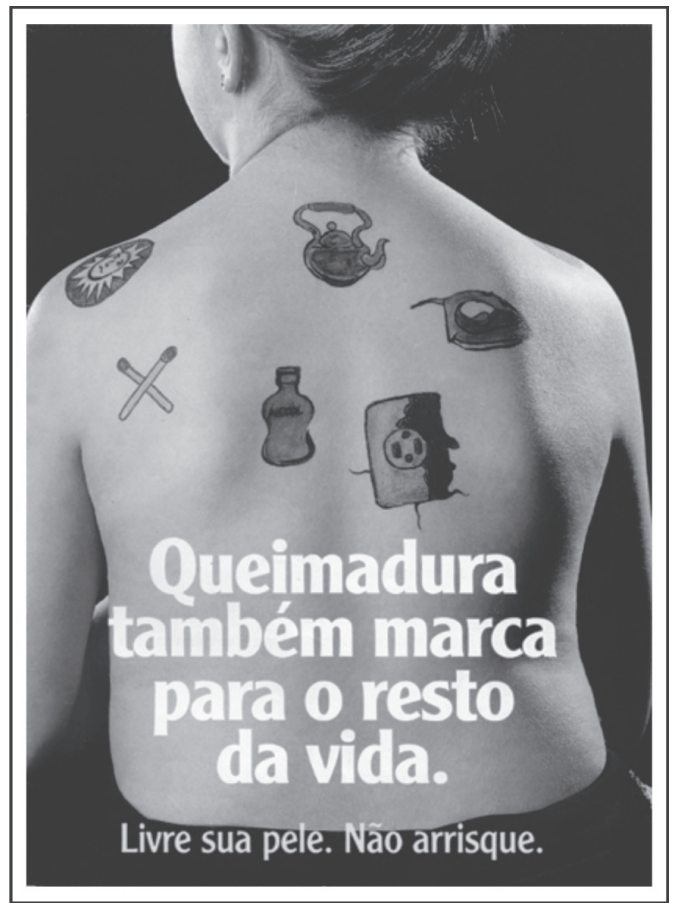

Fonte: Sociedade Brasileira de Queimaduras - Regional Ceará (2001-2003)/Secretaria de Saúde do Estado do Ceará. e desordens, onde um fenômeno se inclina para um ou outro lado de acordo com o ângulo observado ${ }^{15}$. As reinterpretações são evidentes nessas narrativas. Quando Dona Regina enxerta cognitivamente a "prótese-cigarro" na perna amputada de um tabagista, revela a criatividade dos moradores do Dendê. Nas reinterpretações de outros moradores, a "desordem" da realidade social é criticada. Tais críticas das injustiças cotidianas falsificam a ideia de passividade popular nas leituras de campanhas oficiais. Ao contrário, suas palavras revelam que a "doença" não se limita à patologia, mas sim um sofrimento social 5 .

Ouvindo a voz crítica da resignificação popular, os profissionais de saúde aproximam-se da "percepção do mundo visual" 9 popular. Concebem uma "plasticidade perceptual" que corrobora com Katz \& Alegria 7 que desvelaram uma "flexibilização", com transformações nas impressões, entre rígidos pré-conceitos do comportamento humano e comunicação médico-paciente. Mensagens rígidas, autoritárias e sem brechas para reinterpretação, geram resistência popular ${ }^{3}$. Sugerimos imergir na "etnocriação" - campanhas produzidas in loco - junto ao "receptor-cidadão". As múltiplas leituras advêm da criatividade humana, alterando a mensagem emitida para algo palpável na realidade vivenciada. No cerne da pobreza do Nordeste brasileiro, a resignificação é fundamental para a população se perceber e agir ativamente em favor da própria saúde.

\section{Discussão}

Campanhas são elaboradas visando controlar as doenças 6 por equipes especializadas que as padronizam, veiculam e divulgam nos meios de comunicação. As grandes agências publicitárias, em sua maioria, localizadas no Sul e Sudeste do Brasil, são inseridas numa realidade sociocultural distinta do Nordeste. Supõem uma interpretação única da mensagem pela população, utilizando linguagem persuasiva ${ }^{13}$. Essa pesquisa traz prismas diversos de compreensões populares acerca de campanhas em saúde. Berger \& Luckmann ${ }^{8}$, na Teoria da Construção Social da Realidade, argumentam que os indivíduos "constroem" a realidade baseada em crenças, percepções e expectativas culturais. No Brasil, diversas culturas se entrelaçam na formação do povo 14, sendo esperada a resignificação das mensagens num "caleidoscópio de compreensões”, como batizamos. Esse "caleidoscópio" é compreendido à luz da teoria da complexidade de Edgar Morin 15, que retrata o universo como um coquetel de ordens 


\section{Resumo}

De fevereiro de 2009 a novembro de 2010, essa pesquisa antropológica desvelou a compreensão e crítica cultural de três campanhas de comunicação social em saúde no Nordeste brasileiro. Conduzimos 24 entrevistas etnográficas sobre conteúdo iconográfico e semântico das campanhas, na comunidade do Dendê, Fortaleza, Ceará, Brasil. Utilizamos os métodos Análise de Conteúdo, Sistemas de Signos, Significados e Ações e Interpretação Semântica Contextualizada. Entre a elaboração e recepção das mensagens há uma lacuna. Existiram múltiplas interpretações - leitura próxima, caleidoscópio de compreensão e leitura distante - dependendo da proximidade ou afastamento cognitivo da mensagem. Essa "plasticidade perceptual" se deve à criatividade do imaginário popular. O profissional de saúde que ouve - ao invés de descartar - a voz da resignificação subjetiva de mensagens autoritárias aproxima-se da "percepção do mundo visual" dos "receptores". No cerne da pobreza, esse reenquadramento é essencial para a população compreender e agir ativamente em favor da própria saúde.

Comunicação em Saúde; Pobreza; Semântica

\section{Colaboradores}

A coleta de dados foi realizada por K. C. B. M. Diógenes e a redação e revisão final foram realizadas por ambas as autoras.

\section{Agradecimentos}

Aos agentes de saúde comunitários do Centro de Saúde da Família Professor Matos Dourado e aos moradores da comunidade do Dendê.

\section{Referências}

1. Capra F. Ponto de mutação: a ciência, a sociedade e a cultura emergente. São Paulo: Cultrix; 2006.

2. Kleinman A. Writing at the margins: discourse between anthropology and medicine. Berkeley/Los Angeles: University of California Press; 1995.

3. Nations MK, Monte CMG. "I'm not dog, no!": cries of resistance against cholera control campaigns. Soc Sci Med 1996; 43:1007-24.

4. Freire P. Pedagogia da autonomia: saberes necessários à prática educativa. Rio de Janeiro: Editora Paz \& Terra; 2003.

5. Kleinman A. The illness narratives: suffering, healing and the human condition. New York: Basic Books Inc.; 1988.

6. Uchôa E, Vidal JM. Antropologia médica: elementos conceituais e metodológicos para uma abordagem da saúde e da doença. Cad Saúde Pública 1994; 10:497-504.

7. Katz AM, Alegria M. The clinical encounter as local moral world: shifts of assumptions and transformation in relational context. Soc Sci Med 2009; 68:1238-46.

8. Berger PL, Luckmann T. A construção social da realidade: tratado de sociologia do conhecimento. Petrópolis: Editora Vozes; 1990.

9. Hall ET. A dimensão oculta. Rio de Janeiro: Francisco Alves; 1977.

10. Pordeus AMJ, Farias FSAB, Oliveira ER, Moreira TP. Comunidade do Dendê: um diagnóstico de suas famílias. Revista do Centro de Ciências da Saúde; 1999 1:9-17.

11. Bardin L. Análise de conteúdo. Lisboa: Edições 70; 1979.

12. Bibeau G, Corin EE. Beyond textuality: asceticism and violence in anthropological interpretation. Berlin: Mouton de Gruyter; 1995.

13. Berrio J. Teoría social de la persuasión. Barcelona: Mitre; 1983.

14. Ribeiro D. O povo brasileiro. São Paulo: Companhia de Bolso; 2006.

15. Morin E. Ciência com consciência. Rio de Janeiro: Bertrand; 2000.

Recebido em 03/Dez/2010

Versão final reapresentada em 27/Ago/2011

Aprovado em 08/Set/2011 